\title{
KOMBINASI SHUTTLE RUN DAN CORE STABILITY SAMA BAIK DENGAN KOMBINASI SHUTTLE RUN DAN GLUTES CONTROL DALAM MENINGKATKAN KELINCAHAN PEMAIN SEPAK BOLA DI SSB BALI UNITED
}

\author{
Resti Nurpratiwi $^{1}$, I Putu Gede Adiatmika ${ }^{2}$, S. Indra Lesmana ${ }^{3}$, I Wayan \\ Weta $^{4}$, I Putu Adiartha Griadhi ${ }^{2}$, Ni Nyoman Ayu Dewi ${ }^{5}$ \\ ${ }^{1}$ Program Studi Magister Fisiologi Keolahragaan Universitas Udayana, Denpasar \\ ${ }^{2}$ Departemen Ilmu Faal Fakultas Kedokteran Universitas Udayana, Denpasar \\ ${ }^{3}$ Fakultas Fisioterapi Universitas Esa Unggul, Jakarta \\ ${ }^{4}$ Departemen IKK/IKP Fakultas Kedokteran Universitas Udayana, Denpasar \\ ${ }^{5}$ Departemen Biokimia Fakultas Kedokteran Universitas Udayana, Denpasar
}

E-Mail: resti.nurpratiwi123@gmail.com

\begin{abstract}
ABSTRAK
Pendahuluan: Kelincahan suatu kemampuan mengubah posisi dan arah tubuh secara cepat pada saat bergerak dengan kondisi tubuh tetap seimbang. Kelincahan sangat penting bagi pemain sepak bola agar dapat menerobos dan menghindari hadangan lawan serta mengurangi resiko cedera. Pelatihan kelincahan sangat sesuai diberikan bagi pemain sepak bola usia 10-12 tahun yakni dengan pelatihan shuttle run yang dikombinasikan dengan pelatihan stabilisasi, baik berupa core stability maupun glutes control.Tujuan Penelitian: Untuk mengetahui apakah kombinasi shuttle run dan core stability sama baik dengan kombinasi shuttle run dan glutes control dalam meningkatkan kelincahan pemain sepak bola di SSB Bali United. Metode: Penelitian ini adalah penelitian eksperimental, menggunakan rancangan pre and post test group design. Sampel penelitian 22 orang dan di bagi menjadi dua kelompok. Kelompok I mendapat kombinasi shuttle run dan core stability, sedangkan Kelompok II mendapat kombinasi shuttle run dan glutes control. Frekuensi latihan dilakukan 3 kali seminggu selama 6 minggu. Pengukuran kelincahan menggunakan Illinois agility run test. Kelincahan dikatakan meningkat apabila nilai setelah lebih pendek dari nilai sebelum pelatihan. Hasil Penelitian: Didapatkan Kelompok I mengalami peningkatan kelincahan dengan nilai signifikan $\mathrm{p}=0$,01dari nilai kelincahan 19,87 \pm 0 ,94 detik menjadi 15,49 $\pm 0,78$ detik. Demikian juga pada Kelompok II mengalami peningkatan kelincahan dengan nilai signifikan $\mathrm{p}=0,01$ dari nilai kelincahan 19,50 $\pm 0,86$ detik menjadi $15,70 \pm 0,75$ detik. Dari hasil independent $t$-test tidak didapatkan perbedaan dengan nilai sebelum $\mathrm{p}=0,358$ dan sesudah $\mathrm{p}=0,531$. Simpulan : Kombinasi shuttle run dan core stability sama baik dengan kombinasi shuttle run dan glutes control dalam meningkatkan kelincahan pemain sepak bola di SSB Bali United.
\end{abstract}

Kata Kunci: Shuttle run, core stability, glutes control, kelincahan, sepak bola 


\title{
THE COMBINATION OF SHUTTLE RUN AND CORE STABILITY IS AS GOOD AS THE COMBINATION OF SHUTTLE RUN AND GLUTES CONTROL IN INCREASING THE AGILITY OF SOCCER PLAYERS IN SSB BALI UNITED
}

\begin{abstract}
Background: Agility is the ability to change the direction and body position with quickly in a state of movement without losing balance. Agility is very important for soccer players to be able to break through and avoid opponent's obstacles and reduce the risk injury. Agility training is very appropriate for soccer players age 10-12 years with shuttle run training combined with stabilization training in the form of core stability or glutes control. Purpose: to determine whether the combination of shuttle run and core stability is as good as the combination of shuttle run and glutes control in increasing the agility of soccer players in SSB Bali United. Method: This research is an experiment research design with pre and post test group design. The research sample was 22 people, divided into two group. Group I has given a combination of shuttle run and core stability, while Group II has given a combination of shuttle run and glutes control. The frequency of exercise 3 times a week for 6 weeks. Measurement of agility measured a Illinois agility run test. Agility increases if the value after is shorter than the value before training. Result: This study showed that group I increase agility with a significant value of $p=0,01$ with agility value of 19.87 \pm 0.94 seconds to $15.49 \pm 0.78$ seconds. Likewise the group II increase with a significant value of $p=0,01$ with agility value of $19.50 \pm 0.86$ second to $15.70 \pm 0.75$ seconds. Results of the independent t-test there was not difference between group I and Group II, with value before $p=0.358$ and after $p=0.531$. Conclusion: The combination of shuttle run and core stability is as good as the combination of shuttle run and glutes control in increasing the agility of soccer players in SSB Bali United.
\end{abstract}

Keywords: Shuttle run, core stability, glutes control, agility, soccer

\section{PENDAHULUAN}

Sepak bola adalah olahraga permainan dengan waktu 2 x 45 menit. Kelincahan menjadi faktor fisik penting untuk meningkatkan prestasi pemain sepak bola. ${ }^{1}$

Kelincahan merupakan kemampuan mengubah arah dan posisi tubuh secara cepat pada saat bergerak tanpa kehilangan keseimbangan. Kelincahan adalah kombinasi dari kekuatan otot, kecepatan, keseimbangan, koordinasi, fleksibilitas serta kecepatan reaksi. ${ }^{2}$ Kelincahan pada pemain sepak bola dapat berperan untuk menghindari dan menerobos hadangan lawan serta agar atlet tidak mudah jatuh dan cedera pada saat bermain. ${ }^{3}$
Pada pemain sepak bola U 10-12 mereka membutuhkan kelincahan untuk meningkatkan perkembangan gerak mereka dalam mengubah arah tubuh secara cepat, berhenti mendadak serta penyesuaian gerak tubuh saat melakukan permainan sepak bola maupun dalam beraktivitas. ${ }^{4}$ Anak pada usia 10 - 12 tahun berada pada masa perkembangan. Mereka mengalami perkembangan dalam mengkontrol dan mengkoordinasikan anggota gerak tubuh, mulai terjadi penguatan pada otot-otot dan keseimbangan. ${ }^{5}$

Banyak metode untuk meningkatkan kelincahan. Pelatihan kelincahan yang cocok untuk pemain sepak bola U 10-12 tahun bisa dengan pemberian pelatihan dalam bentuk 
permainan yang bisa ditemukan dalam permainan sehari-hari, salah satunya adalah pelatihan shuttle run.

Shuttle run adalah pelatihan yang tidak bersifat pembebanan sehingga dapat diberikan pada semua usia dan termasuk model pelatihan kelincahan yang baik untuk diterapkan pada anak usia 10-12 tahun. ${ }^{6}$

Shuttle run merupakan pelatihan berlari dengan cepat secara bolak-balik dari titik satu ke titik lain. ${ }^{7}$ Dalam meningkatkan kelincahan tidak hanya berfokus pada pelatihan kelincahan saja melainkan juga memperhatikan komponen lain yang membentuk sebuah kelincahan, salah satu komponennya adalah stabilisasi. ${ }^{8}$

Stabilisasi didefinisikan sebagai kemampuan untuk mengkontrol posisi dan pergerakan. ${ }^{9}$ Stabilitas diperlukan untuk menjaga postur tubuh tetap pada bidang tumpu agar kerja sistem muskuloskeletal menjadi minimal sehingga akan menghasilkan gerakan yang efisien. ${ }^{8}$ Untuk mendapatkan stabilitas yang baik bisa di dapat dengan pemberian pelatihan stabilisasi berupa pelatihan stabilisasi trunk yaitu dengan core stability dan pelatihan stabilisasi hip yaitu glutes control.

Core stability dapat meningkatkan stabilitas, keseimbangan, fungsi sensomotoris serta memudahkan tubuh agar dapat bergerak secara efektif dan efisien. ${ }^{10}$ Core stability dapat memberikan kontrol posisi dan gerakan pada tubuh saat terjadi perubahan arah dan gerakan yang berpindahpindah. ${ }^{11}$

Gluteus control adalah bentuk pelatihan yang bertujuan untuk meningkatkan kekuatan otot gluteus sebagai stabilisator aktif dari sendi hip yang mempengaruhi kerja dari gerakan otot tungkai. ${ }^{12}$

Pada pelatihan yang disebutkan di atas sudah banyak referensi jurnal yang membahas mengenai pelatihan shuttle run dan core stability terhadap kelincahan namun untuk pelatihan glutes control masih sedikit referensi yang membahas pelatihan ini terhadap kelincahan. Padahal secara teori pelatihan glutes control juga merupakan pelatihan yang dapat meningkatkan kelincahan. Pelatihan glutes control dan core stability sama-sama dapat memberikan efek terhadap stabilisasi tubuh sehingga mampu meningkatkan kelincahan.

Berdasarkan latar belakang permasalahan, penulis memutuskan melakukan penelitian di SSB Bali United dengan tujuan untuk membandingkan intervensi mana yang lebih baik untuk meningkatkan kelincahan pemain sepak bola.

\section{METODE PENELITIAN}

Rancangan penelitian bersifat eksperimental dengan pre and post test group design. Kelompok I diberikan kombinasi shuttle run dan core stability, sedangkan Kelompok II diberikan kombinasi shuttle run dan glutes control. Pengukuran kelincahan menggunakan Illinois Agility Run Test. Kelincahan dikatakan meningkat apabila nilai sesudah lebih pendek dari nilai sebelum pelatihan.

Penelitian ini dilakukan di Lapangan Niti Mandala Renon, Panjer, Kec. Denpasar Timur, Kota Denpasar, Bali. Penelitian berlangsung mulai bulan Januari - Maret 2020. Penelitian dilakukan selama 6 minggu sebanyak 3 kali dalam seminggu. Jumlah sampel adalah 22 orang, dibagi menjadi dua kelompok sehingga tiap kelompok 11 orang.

\section{HASIL PENELITIAN}

\section{Karakteristik Subjek Penelitian}

Tabel 1.

Karakteristik Sampel

\begin{tabular}{lccc}
\hline Karakteristik & $\begin{array}{c}\text { Kelompok I } \\
(\text { Rerata } \pm \text { SB })\end{array}$ & $\begin{array}{c}\text { Kelompok II } \\
(\text { Rerata } \pm \text { SB })\end{array}$ & $\mathrm{p}$ \\
\hline Umur (tahun) & $11,36 \pm 0,67$ & $11,27 \pm 0,64$ & 0,750 \\
Berat Badan $(\mathrm{kg})$ & $143,91 \pm 6,87$ & $143,00 \pm 7,81$ & 0,775 \\
Tinggi Badan (cm) & $36,54 \pm 5,78$ & $36,00 \pm 5,55$ & 0,824 \\
IMT (kg/cm) & $17,54 \pm 1,46$ & $17,50 \pm 1,16$ & 0,953 \\
\hline
\end{tabular}

Tabel 1 menunjukan bahwa tidak terdapat perbedaan bermakna pada karakteristik subjek penelitian dari ke dua kelompok sebelum pelatihan dengan nilai $p>0,05$ maka masing-masing kelompok memiliki 
karakteristik yang sama.

\section{Uji Normalitas dan Homogenitas}

Tabel 2.

Uji Normalitas dan Homogenitas

\begin{tabular}{lccc}
\hline & \multicolumn{2}{c}{ Uji Normalitas* } & Uji \\
\cline { 2 - 3 } & $\begin{array}{c}\text { Kelompok I } \\
\mathrm{p}\end{array}$ & $\begin{array}{c}\text { Kelompok II } \\
\mathrm{p}\end{array}$ & Homogenitas ** \\
\hline Sebelum & 0,737 & 0,753 & 0,642 \\
\hline Sesudah & 0,230 & 0,762 & 0,759 \\
\hline
\end{tabular}

*Uji Normalitas dengan Saphiro Wilk test

**Uji Homogenitas dengan Levene's test

Berdasarkan Tabel 2, keseluruhan data pada uji normalitas dan homogenitas memiliki nilai $\mathrm{p}>0,05$ maka menunjukan seluruh data tiap kelompok berdistribusi normal dan homogen.

\section{Uji Beda Rerata Kelincahan}

Tabel 3

Paired Sample t-test

\begin{tabular}{lccl}
\hline & $\begin{array}{c}\text { Sebelum } \\
(\text { Rerata } \pm \text { SB }) \\
(\text { detik })\end{array}$ & $\begin{array}{c}\text { Sesudah } \\
(\text { Rerata } \pm \text { SB }) \\
(\text { detik })\end{array}$ & p \\
\hline Kelompok I & $19,87 \pm 0,94$ & $15,49 \pm 0,78$ & 0,01 \\
Kelompok II & $19,50 \pm 0,86$ & $15,70 \pm 0,75$ & 0,01
\end{tabular}

Berdasarkan Tabel 3, didapatkan hasil dari uji paired bahwa nilai $\mathrm{p}=0,01(<0,05)$ yang berarti pada ke dua kelompok terjadi perubahan peningkatan kelincahan antara sebelum dan sesudah pelatihan secara bermakna dan signifikan. Karena itu dapat dikatakan bahwa kedua jenis pelatihan dapat meningkatkan kelincahan pada pemain sepak bola.

\section{Uji Komparasi Kelincahan Sebelum dan Sesudah Pelatihan antar Kelompok}

Tabel 4

Independent Sample t-test

\begin{tabular}{cccc}
\hline & $\begin{array}{c}\text { Kelompok I } \\
\text { Rerata } \pm \text { SB }) \\
(\text { detik })\end{array}$ & $\begin{array}{c}\text { Kelompok II } \\
(\text { Rerata } \pm \text { SB }) \\
(\text { detik })\end{array}$ & $\mathrm{p}$ \\
\hline Sebelum & $19,87 \pm 0,94$ & $19,50 \pm 0,86$ & 0,358 \\
\hline Sesudah & $15,49 \pm 0,78$ & $15,70 \pm 0,75$ & 0,531 \\
\hline Pada & Tabel 4 & didapatkan hasil uji
\end{tabular}
independent didapatkan nilai $p$ sebelum pelatihan 0,358 dan sesudah pelatihan 0,531 sehingga nilai $\mathrm{p}>0,05$ yang berarti tidak ada perbedaan peningkatan kelincahan yang bermakna di antara ke dua kelompok baik sebelum maupun setelah dilakukannya pelatihan. Sehingga kombinasi shuttle run dan core stability sama baik dengan kombinasi shuttle run dan glutes control dalam meningkatkan kelincahan pemain sepak bola.

\section{PEMBAHASAN}

\section{Karakteristik Subjek Penelitian}

Umur yang dilibatkan sebagai subjek penelitian yaitu pemain sepak bola berusia 10-12 tahun dan semua subjek penelitian memiliki IMT yang normal. Pada Tabel 1 didapatkan hasil data sebelum diberikan pelatihan pada ke dua kelompok tidak memiliki perbedaan karakteristik subjek.

Kelincahan dipengaruhi oleh faktor usia, jenis kelamin, tinggi badan dan berat badan. ${ }^{13}$ Kelincahan seorang anak akan meningkat hingga usia 12 tahun. Selama priode tersebut (3 tahun) kelincahan tidak meningkat bahkan menurun. Setelah itu kelincahan meningkat kembali hingga anak mencapai maturitas dan menurun kembali setelah itu. ${ }^{14}$

Tinggi badan adalah bagian dari antropometri yang berpengaruh terhadap kemampuan kelincahan seseorang. Berat badan berlebih dapat mengurangi kelincahan akibat adanya friksi jaringan lemak pada serabut otot sehingga kontraktilitas otot menjadi berkurang. ${ }^{15}$ Terdapat hubungan signifikan antara IMT dan kelincahan. ${ }^{16}$

Perbandingan Kombinasi Shuttle Run dan Core Stability Dengan Kombinasi Shuttle Run dan Glutes Control Terhadap Peningkatan Kelincahan

Berdasarkan analisis data nilai kelincahan sebelum dan setelah pelatihan pada Tabel 3 didapatkan nilai $\mathrm{p}=0,01$ $(\mathrm{p}<0,05)$, sehingga terjadi peningkatan kelincahan pada Kelompok I dan II. Dari hasil tersebut dapat disimpulkan kombinasi 
shuttle run dan core stability dengan kombinasi shuttle run dan glutes control dapat meningkatkan kelincahan.

Pelatihan pada pemula yang diberikan dalam jangka waktu 6-8 minggu dengan frekuensi pelatihan 3-4 kali seminggu memberikan efek adaptasi tubuh dengan pelatihan sehingga dapat menghasilkan peningkatan. ${ }^{17}$

Pada program latihan, pada minggu pertama dan ke dua belum mengalami peningkatan pada kekuatan otot, karena pada minggu tersebut masih dalam penyesuaian terhadap gerakan, kemudian minggu ke tiga dan ke enam otot terbentuk karena setiap minggunya repetisi ditambah sehingga otototot tersebut menjadi kuat karena ada rangsangan otot dalam pengulangan latihan. Frekuensi latihan yang efektif untuk kelincahan sebaiknya dilakukan 3 kali dalam seminggu. ${ }^{18}$

Shuttle run adalah suatu bentuk latihan kemampuan mengubah arah secara cepat sambil melakukan gerakan bolak- balik yang dapat membentuk kelincahan saat mengubah gerak badan dalam permainan sepak bola. Pemberian pelatihan shuttle run memberikan pengaruh peningkatan nilai kelincahan dari sebelum dan sesudah pelatihan shuttle run. ${ }^{19}$

Sedangkan tambahan kombinasi pada Kelompok I yaitu core stability mampu mengkontrol posisi dan gerak dari trunk untuk melakukan perpindahan, kontrol tekanan dan gerakan secara optimal saat beraktivitas. ${ }^{20}$

Pelatihan core yang dilakukan selama 4 minggu mengakibatkan terjadinya peningkatan kecepatan dan juga kelincahan. ${ }^{21}$ Pemberian pelatihan core stability secara intensif akan meningkatkan kelincahan seseorang. Dalam pelatihan core stability memberikan kekuatan otot postural, hal tersebut dapat meningkatkan stabilitas trunk dan postur, maka gerakan menjadi lebih stabil dan seimbang, sehingga mampu meningkatkan kemampuan kelincahan. ${ }^{22}$

Beberapa penelitian di atas diketahui bahwa metode core stability dapat meningkatkan kelincahan. Sehingga penambahan core stability pada latihan shuttle run dapat membuat latihan shuttle run menjadi lebih efektif karena latihan shuttle run merupakan latihan kemampuan mengubah arah gerakan bolak-balik secara cepat. Gerakan bolak-balik pada latihan shuttle run membutuhkan keseimbangan yang baik. Penambahan core stability ini memberikan penambahan stabilisasi tubuh sehingga tubuh menjadi lebih seimbang sehingga akan terciptanya pelatihan shuttle run yang efisien. Penerapan pelatihan shuttle run yang efisien secara rutin dapat meningkatkan kelincahan secara lebih baik.

Penjelasan di atas sesuai dengan penelitian sebelumnya di mana pemberian core stability dan shuttle run dapat meningkatkan kelincahan. Dapat disimpulkan bahwa hasil penelitian sebelumnya sama dengan penelitian yang dilakukan oleh peneliti, yaitu menunjukan terjadi adanya peningkatan kelincahan pada pemain sepak bola menggunakan pelatihan core stability dan shuttle run. ${ }^{10}$

Pada Kelompok II diberikan tambahan kombinasi latihan yaitu glutes control. Gluteus control bertujuan untuk meningkatkan kekuatan otot gluteus sebagai stabilisator aktif dari sendi hip. Pemberian pelatihan glutes control secara rutin dapat membuat otot glutes menjadi lebih kuat dan dapat meningkatkan performa kinerja dari otot tersebut. Pada pelatihan glutes, otot glutes maximus membantu atlet dalam kelincahan dan mendorong atlet berlari lebih cepat sedangkan otot glutes medius dan minimus berperan sebagai stabilisasi pinggul saat berjalan. ${ }^{23}$ Otot glutes merupakan hal 
penting dalam akselerasi, khususnya dalam meningkatkan kecepatan, yang terjadi karena meningkatnya daya dari glutes. Selain itu penguatan glutes meningkatkan kelincahan, daya ledak, dribbling dan kekuatan menendang pada pemain sepak bola. ${ }^{24}$

Berdasarkan penjelasan di atas dapat dinyatakan bahwa glutes control dapat meningkatkan kelincahan. Sejalan dengan penelitian ini bahwa pelatihan glutes control dapat meningkatkan kelincahn pada pemain sepak bola di SSB Bali United. Pelatihan shuttle run merupakan pelatihan yang banyak menggunakan anggota badan extremitas bawah. Pada pelatihan shuttle run tubuh berlari secepat mungkin dengan merubah arah secara bolak-balik. Pada perubahan arah ini tubuh membutuhkan keseimbangan. Pelatihan glutes control memberikan stabilisasi pada hip sehingga terciptanya keseimbangan pada extremitas bawah pada saat pelatihan shuttle run. Selain itu glutes control juga meningkatkan kekuatan otot glutes yang mengakibatkan terjadinya peningkatan panjang langkah saat pelatihan shuttle run dikarenakan adanya peningkatan daya dorong dari otot glutes. Sehingga penambahan glutes control pada pelatihan shuttle run dapat membuat pelatihan shuttle run menjadi lebih efisien. Pelatihan shuttle run yang lebih efektif akan menghasilkan kelincaha yang lebih efektif juga akibat adaptasi tubuh dari pelatihan yang rutin.

\section{Kombinasi Shuttle Run dan Core Stability Sama Baik Dengan Kombinasi Shuttle Run dan Glutes Control Dalam Meningkatkan Kelincahan}

Dari hasil analisis statistik menggunakan Independent sampel $t$ test pada Tabel 4 didapatkan bahwa tidak ada perbedaan bermakna antara ke dua kelompok dalam meningkatkan kelincahan. Maka dapat disimpulkan bahwa kombinasi shuttle run dan core stability sama baik dengan kombinasi shuttle run dan glutes control dalam meningkatkan kelincahan pemain sepak bola.

Hal ini disebabkan karena pelatihan shuttle run merupakan pelatihan kelincahan yang jika dilakukan secara rutin maka akan meningkatkan kelincahan. Kemudian tambahan kombinasi perlakuan Kelompok I yaitu core stability pada dasarnya ditujukan untuk otot core sehingga terjadinya stabilisasi pada trunk.Sedangkan pada tambahan kombinasi perlakuan Kelompok II yaitu glutes control ditujukan untuk otot glutes sehingga terjadinya stabilisasi pada hip. Penambahan core stability dan glutes control pada shuttle run sebenarnya memiliki kesamaan tujuan yaitu untuk stabilisasi dengan mengaktifkan otot-otot yang berperan dalam kelincahan. Hanya saja memiliki perbedaan dari segi otot target yang diaktivasi. Sehingga dapat dipilih salah satu di antara ke dua pelatihan tersebut.

Faktor lain tidak adanya perbedaan hasil antara ke dua kelompok dikarenakan usia pada subjek penelitian ini. Core stability dan glutes control adalah latihan stabilisasi yang termasuk dalam jenis latihan kontraksi isometrik. Latihan kontraksi isometrik merupakan bentuk latihan statik dimana tidak ada perubahan panjang otot dan pergerakan sendi, sehingga ketegangan otot bertambah namun panjang otot tetap. Sedangkan latihan stabilisasi adalah latihan pembebanan dengan menggunakan berat badan tubuh. ${ }^{9}$ Kondisi fisik pada anak usia 10-12 tahun masih mengalami perkembangan sehingga ototnya belum cukup kuat untuk melakukan pelatihan berupa latihan kontraksi isometrik, serta pelatihan kontraksi isometrik juga belum terlalu dibutuhkan pada usia tersebut. Selain 
itu nilai kelincahan pada anak-anak akan selalu meningkat setiap tahunnya. Pada usia 3-13 tahun, memperlihatkan peningkatan kelincahan dengan anak laki-laki memperbaiki 0,5 detik setiap tahunnya. ${ }^{25}$

Berbagai faktor eksternal juga dapat mempengaruhi tidak adanya perbedaan hasil antara ke dua kelompok. Suhu udara yang tinggi dapat meningkatkan suhu badan. Berolahraga akan menambah suhu menjadi lebih panas. Sehingga terjadi penimbunan panas yang semakin banyak (heatstroke).

Kecepatan angin yang terlalu tinggi dapat menghambat pergerakan sehingga dapat mempengaruhi kelincahan. Lapangan yang rata (tidak bergelombang) mempermudah pemain tampil lincah dalam permainan. Semakin tinggi tempat berlatih kadar oksigen semakin rendah. Pada daerah dataran rendah memiliki udara yang panas serta tanah yang landai. Sedangkan dataran sedang adalah perbukitan yang memiliki ketinggian kurang dari 600 meter di atas permukaan laut. Dataran tinggi memiliki udara yang sejuk, dingin, curah hujan tinggi serta kondisi tanah yang berkelok dan turun naik. Penggunaan sepatu yang baik untuk pemain sepak bola adalah sepatu sepak bola yang aman dan nyaman bagi penggunanya sehingga tidak mengganggu jalannya pelatihan maupun pertandingan serta menghindari terjadinya cedera.

Otot core merupakan hal yang penting dalam fungsi core dan punggung, namun ada banyak otot lain yang perlu diaktivasi secara khusus untuk memastikan core sepenuhnya dikembangkan. Core merupakan pelatihan umum yang dibutuhkan oleh seorang atlet. Namun penguatan core membutuhkan peran dari otot glutes. Penelitian mengatakan aktivitas kelincahan dalam berlari memerlukan core yang kuat dan aktivasi glutes yang cukup untuk memfasilitasi mekanik berjalan yang efisien. ${ }^{26}$
Pelatihan core dan glutes adalah pelatihan mendasar dan efisien yang digunakan untuk meningkatkan kelincahan. $^{27}$ Kombinasi dari core stabilization dan strength, aktivasi gluteus dan piriformis dapat menjadi program stimulasi yang komplit. Karena jika pelatihan hanya difokuskan pada otot-otot anterior core maka akan terjadi ketidakseimbangan. Dikatakan bahwa penguatan core yang dibarengi dengan aktivasi glutes akan menghasilkan performa yang sukses dan baik. ${ }^{28}$

Berdasarkan pendapat di atas, dapat memungkinkan pemberian shuttle run yang dikombinasikan dengan pelatihan core stability dan glutes control akan menghasilkan pelatihan shuttle run yang lebih efektif. Karena pada saat penambahan core stability dan glutes control pada pelatihan shuttle run maka tubuh akan mendapatkan double stabilisasi, yaitu stabilisasi dari trunk untuk stabilisasi postural pada saat melakukan gerakan awal dan stabilisasi dari hip untuk extremitas bawah yang digunakan saat kaki melangkah. Pelatihan shuttle run adalah pelatihan kelincahan sehingga saat melakukan pelatihan shuttle run yang lebih efektif secara rutin maka akan meningkatkan kelincahan yang lebih baik.

\section{KETERBATASAN PENELITIAN}

1. Peneliti tidak dapat mengkontrol aktivitas sampel yang dilakukan di luar jam penelitian.

2. Kondisi cuaca lingkungan yang tidak dapat dikontrol dikarenakan penelitian dilakukan di lapangan terbuka.

\section{SIMPULAN}

1. Kombinasi shuttle run dan core stability dapat meningkatkan kelincahan pemain sepak bola di SSB Bali United. 
2. Kombinasi shuttle run dan glutes control dapat meningkatkan kelincahan pemain sepak bola di SSB Bali United.

3. Kombinasi shuttle run dan core stability sama baik dengan kombinasi shuttle run dan glutes control dalam meningkatkan kelincahan pada pemain sepak bola di SSB Bali United.

\section{SARAN}

1. Bagi peneliti berikutnya, jika ingin mengambil masalah yang sejenis diharapkan dapat meneliti mengenai apakah kombinasi antara pelatihan shuttle run, core stability dan glutes control lebih baik dalam meningkatkan kelincahan pemain sepak bola yang jika dibandingkan hanya dengan kombinasi pelatihan shuttle run dan core stability ataupun kombinasi pelatihan shuttle run dan glutes control saja.

2. Kepada para pelatih dan atlet khususnya pada cabang olahraga sepak bola bahwasanya kombinasi shuttle run dan core stability sama baik dengan kombinasi shuttle run dan glutes control dalam meningkatkan kelincahan pemain sepak bola di SSB Bali United. Sehingga pelatih maupun pemain sepak bola dapat memilih salah satu di antara ke dua pelatihan ini.

\section{DAFTAR PUSTAKA}

1. Surohudin. 2013. Pengaruh Latihan Ballnastic Terhadap Kelincahan Pada Pemain Sepak Bola Usia 15-18 Tahun. Surabaya: Artikel E-Jurnal UNESA.

2. Ismaryati. 2008. Peningkatan Kelincahan Atlet melalui Penggunaan Metode Latihan Sirkuit Plyometrik dan Berat Badan. Paedagogia, 11 (1), 74-89.

3. Faruq. 2008. Meningkatkan Kebugaran Tubuh Melalui Permainan dan Olahraga Sepakbola. Indonesia:Grasindo.

4. Dawes, J and Mark R. 2011. Developing Agility and Quickness. US: Sport Performance Series.
5. Desmita. 2012. Psikologi Perkembangan Peserta Didik, Bandung: PT. Remaja Rosdakarya.

6. Rakhmawati, A.A. 2019. Pengaruh Kombinasi Shuttle Run dan Bounce and Catch Reaction Ball Terhadap Peningkatan Agility Usia 10-12 Tahun Di MI MA' ARIF PADEMONEGORO. [Skripsi] Malang: Universitas Muhammadiyah Malang.

7. Marjana, W., Sudiana, I. K., Kes, S. P. M., dan Made Budiawan. S. K. 2014. Pengaruh Pelatihan Shuttle Run Terhadap Kecepatan dan Kelincahan. Jurnal Ilmu Keolahragaan Undiksha. 2 (1).

8. Pramita, I., Setiawan and Zuhri, S. 2017. Pengaruh Latihan Stabilisasi Postural Terhadap Keseimbangan Statis Dan Dinamis Pada Pasien Pasca Stroke. Jurnal Kesehatan Terpadu. 1 (1) : 19-24.

9. Kisner and Colby. 2007. Therapeutic Exercise: Foundation and Techniques. Fifth Edition, Philadelphia : F. A. Davis Company, 1915 Arch Street.

10. Ramadan, F. 2017. Pengaruh Pemberian Core Stability Exercise dan Latihan Shuttle Run terhadap Peningkatan Agility Pemain Futsal. Surakarta: Universitas Muhammadiyah Surakarta.

11. Chabut. 2009. Core Strength For Dummies. U.S.A: Wiley Publishing.

12. Lieberman, D. E. 2006. The human gluteus maximus and its role in running. USA: Department of Anthropology, University of Arizona.

13. Hadinoto dan Dwi , P.2009. Sumbangan Panjang Tungkai dan Kelincahan terhadap Kecepatan Tendangan Sabit pada Atlet Tapak Suci di Pondok Pesantren Dahrul Ihsan Sragen Tahun 2008. Skripsi. Fakultas Ilmu Keolahragaan Universitas Negri Semarang, Semarang. 
14. Moeloek, D dan Tjokro, A. 1984. Kesehatan dan Olahraga. Jakarta:Fakultas Kedokteran Universitas Indonesia.

15. Rudiyanto. 2012. Hubungan Berat Badan Tinggi Badan dan Panjang Tungkai dengan Kelincahan. Journal of Sport Sciences and Fitness. 1 (2).

16. Parseh, Abed and MH Soolhjo. 2015. Studying The Relationship Between Body Mass Index With Speed, Agility and Balance In Male Student Of 15-13 Years Old. Indian Journal of Fundamental and Applied Life Sciences. $5(2)$.

17. Nala, I.GN. 2011. Prinsip Pelatihan Fisik Olahraga. Denpasar : Komite Olahraga Nasional Indonesia Daerah Bali.

18. Bompa. 2009. Periodization Training For Sport: Program For peak Strenght In 25 Sports United State Of America. Human Kinetic.

19. Alamsyah, K,A. 2016. Pengaruh Latihan Shuttle Run Dan Lari Zig-Zag Terhadap Keterampilan Dribbling Dalam Permainan Bola Basket Pada Siswa SMP Negeri 1 Biromaru.

20. Karren, Saunders, Chabut and Lareine. 2008. Core Strength For Dummies. Canada.

21. Araujo, Hayes, Lawrence, Cohen, Deniel dan Simone. 2016. Six weeks of Core Stability Training Improve Landing Kinetics Among Female Capoira Athletes: A pilot study. Journal of Human Kinetics. 45, 27-37.

22. Irfan, M. 2012. Core Stability Exercise Pada Latihan Otot Dasar Panggul Dalam Temu Ilmiah Tahunan Fisioterapi Indonesia XXVII. Medan: Ikatan Fisioterapi Indonesia.

23. Julia, K. 2019. The Truth abaout Glutes and Glutes Activation. https://www.relentlessathleticsllc.com/ed ucation/2019/03/the-truth-about-glutesand-glute-activation.

24. Raj. 2016. Effect of glute strengthening training with foam rollers and resistance training on selected physical physiological and skill related variables among football players.

25. Purnama, A. 2016. Pengaruh Gymnastics Pada Kecepatan dan Kelincahan Anak Indonesia. Jurnal Kesehatan Olahraga. 6 (2).

26. Michael, H. 2015. Get Ahead With The Curve: Gluteal Activation for Runner. https://www.fleetfeet.com/s/pdx/news/get -ahead-with-the-curve-gluteal-activationfor-runners.

27. Czaprowski, D., Kedra, A. And Biernat, R. 2012. Student's Knowledge Concerning the Correct Squat and the Elements of the Methodology of Teaching it. Baltic Journal of Health and Physical Activity, 4(2): 124-131.

28. Paul. J, G. 2009. Connecting The Core. NNSCA's Performance Training Journal, 3 (6). 